\title{
Caracterización de la poética del cine de animación infantil
} Characterization of the poetics of animated film

\author{
Luis Ángel Esparza Santa María \\ Universidad Nacional Mayor de San Marcos, Lima, Perú \\ luis.esparza@unmsm.edu.pe \\ ORCID: https://orcid.org/0000-0001-8544-3537
}

\section{Resumen}

La producción de un guion de animación infantil es un proceso delicado por varios factores: la naturaleza de un guion, que no basta con ser escrito, sino que debe ser producido para cumplir su cometido; los altos costos de la producción audiovisual, que lo obligan a incluir valores comerciales en su poética para garantizar una recuperación de la gran inversión; las demandas de un público altamente segmentado, como lo es el infantil; y las demandas de una sociedad que exige altos valores comerciales de las industrias culturales. En ese sentido, el objetivo central del presente artículo es proponer una caracterización del cine de animación infantil orientado a tres ejes: el comercial (que cumple con los requerimientos del público), el autoral (que respeta la poética del autor) y el híbrido (que balancea ambos intereses). Para lograrlo, se ha establecido un marco teórico orientado a la cultura de masas basado en Mario Vargas Llosa y Umberto Eco. Adicionalmente, se ha consultado a Robert McKee como teórico del guion audiovisual. Con esta base se ha propuesto una caracterización del cine de animación infantil que, luego del análisis y descripción de algunos ejemplos, arroja como resultados mucha variedad en la temática y estilo del cine autoral, lo que hace a este eje muy personal y libre; y evidentes similitudes en el cine comercial, que hacen a este eje uno fácilmente categorizable, y por lo tanto adaptable a una propuesta híbrida de cine animado. Lo conclusión principal es que una categorización como esta es necesaria para crear una propuesta híbrida de cine de animación infantil, necesaria en una industria aún naciente.

Palabras clave Cine, animación, guion, escritura creativa

\begin{abstract}
The writing of a screenplay for an animated film for children is a delicate process due to several factors: the nature of a script, whose goal is not only to be written, but must also be produced to fulfill its purpose; the high costs of audiovisual production, which oblige it to include commercial values in its poetics to guarantee a recovery of the large investment; the demands of a highly segmented public, such as children; and the demands of a society that expects high commercial values
\end{abstract}


from cultural industries. In this sense, the main goal of this article is to propose a characterization of children's animation cinema based on three axes: the commercial (in order to meet the audience's requirements), the authorial (in order to respect the author's poetics) and the hybrid (which balances both interests). To achieve this, a theoretical framework oriented to mass culture based on Mario Vargas Llosa and Umberto Eco has been established. Additionally, Robert McKee has been consulted as the theorist of the audiovisual script. On this basis, a characterization of children's animation cinema has been proposed that, after analyzing and describing some examples, yields as a result great variety in the subject matter and style of authorial cinema, which makes this axis very personal and free; and obvious similarities in commercial cinema, which make this axis easily categorized, and therefore adaptable to a hybrid proposal of animated cinema. The main conclusion is that a categorization like this is necessary to create a hybrid proposal for children's animated cinema, necessary in a still nascent industry.

Keywords Film, animation, screenplay, creative writing

Fecha de envio: 2/3/2021 Fecha de aceptación: 30/5/2021

\section{Introducción}

Existen varios medios para la escritura creativa: el ensayo, la narrativa, la poesía, el teatro y el guion cinematográfico. Listamos el guion cinematográfico al final porque efectivamente lo está. Vive en la frontera entre lo que es y no es literatura. Es literatura pensada no para ser leída, sino para ser interpretada. Pueden ser obras hermosas, pero son subproductos, solo herramientas para plasmar ideas en escena.

Existen tres elementos teóricos de análisis en un guion cinematográfico: su retórica, su poética y su estética. En el caso de la retórica de un guion, esta consiste en la utilización del lenguaje en el texto y su capacidad persuasiva. El guion tiene una escritura restringida y ambigua que renuncia a la descripción y al símil en búsqueda de la cámara. Contiene la pauta necesaria para la acción y la construcción de la historia y además genera atmósferas. Sin embargo, tiene una labor adicional de persuasión. ¿A quién debe persuadir un guion? ¿Quién lo lee y por qué?

La poética del guion se encarga de los elementos dentro del mismo guion y su combinación para lograr determinados objetivos. Se trata de la estructura narrativa, los elementos del argumento, los personajes, los actantes, la iconografía planteada, las unidades concretas o escenas, los saltos temporales, los puntos de vista y demás. La pregunta clave es: ¿cuál es la razón por la que los elementos se encuentren como están en el guion? ¿A qué responden las opciones poéticas dentro del guion? 
Finalmente, la estética de un guion se refiere a las imágenes acústicas y visuales planteadas, los espacios fílmicos desarrollados, diversas yuxtaposiciones, semejanzas, transiciones o sinestesias que el autor ubica para atrapar a un lector. Es lo que hace que un guion sea bello, lo que hace que trascienda su característica de medio en función de un fin, es lo que vuelve al guion un fin en sí mismo y lo ubica a la zaga de la lista de medios para desarrollar escritura creativa. Como en el caso de la poética, surgen preguntas referentes a las razones para tomar las decisiones estéticas tomadas. ¿Para qué se toman? ¿Por qué esta transición y no aquella? ¿Por qué la repetición de esa imagen?

Retórica, poética y estética. Todas nos dejan con preguntas a responder, y las respuestas orientan nuestra mirada hacia el público. ¿La razón? El cine es muy caro. Mientras que un poemario o una novela puede ser escrita en la soledad de una habitación que cobija al escritor y sus ideas, el guion no tiene sentido bajo este esquema. Como se planteó anteriormente, un guion no está hecho para ser publicado. Ese no es su fin, porque en esencia el guion es solo un medio. El guion debe ser producido, y para lograrlo el guionista debe pensar no solo en la poética (orientada hacia la narración efectiva de la historia) y la estética (orientada al disfrute del texto mismo como abanico de posibilidades estilísticas auditivas y visuales), sino también en la retórica. ¿A quién debe persuadir el guion para, eventualmente, con empuje, suerte (y mucho dinero), ser producido? A un inversionista, un auspiciador o un jurado. Agentes externos, no literarios, más afines con el mercado que con el artista. Además de contar una historia bien y ser una obra digerible a nivel de lectura, el guion debe convencer de que la historia que cuenta atraerá público al cine.

Existen numerosas excepciones a lo mencionado, como lo demuestran cientos de películas autorales, difíciles y herméticas que se han abierto paso hacia las salas de cine y han tomado su lugar en la historia de la cinematografía mundial. Sin embargo, si el proyecto propuesto es de animación, los problemas se multiplican. Este medio está altamente segmentado, con presupuestos altísimos y un público fuertemente determinado. El público debe ser un eje central en el quehacer creador. Esto nos obliga a retroceder a una pregunta planteada líneas atrás: ¿es posible hacer un buen guion para un público masivo? Cinematografías con industrias desarrolladas como la francesa, la japonesa o la estadounidense nos demuestran que sí. La peruana, aún incipiente y sometida a un público con grandes deficiencias culturales, se encuentra aún en el proceso de aprendizaje. Nos toca a los creadores encontrar ese balance entre público y calidad. Es nuestra labor escribir películas buenas que no alienen al público, para garantizar el crecimiento de la industria. Debemos evitar la complacencia fácil y la narrativa hermética. Debemos encontrar un punto medio. 


\section{Antecedentes y objetivos}

Vivimos en una sociedad ya hace mucho tiempo consumida por la cultura de masas. Y el guion, objeto de estudio del presente artículo, vive por definición en los confines de dicha cultura. En ese sentido los estudios de interés para el presente proyecto son los que analizan la cultura de masas, como los de Umberto Eco, Gilles Lipovetsky, Alvin Toffler y Mario Vargas Llosa, citados líneas más abajo. Estos dan luces de una sociedad obsesionada con el entretenimiento, análisis obligatorio para un estudio de esta índole:

La diferencia esencial entre aquella cultura del pasado y el entretenimiento de hoy es que los productos de aquella pretendían trascender el tiempo presente, durar, seguir vivos en las generaciones futuras, en tanto que los productos de este son fabricados para ser consumidos al instante y desaparecer, como los bizcochos o el popcorn. Tolstói, Thomas Mann, todavía Joyce y Faulkner escribían libros que pretendían derrotar a la muerte, sobrevivir a sus autores, seguir atrayendo y fascinando lectores en los tiempos futuros. Las telenovelas brasileñas y las películas de Bollywood, como los conciertos de Shakira, no pretenden durar más que el tiempo de su presentación, y desaparecer para dejar el espacio a otros productos igualmente exitosos y efímeros. La cultura es diversión y lo que no es divertido no es cultura (Vargas Llosa, 2012, p. 31).

Sin afán de desacreditar opiniones como la mencionada, la búsqueda del presente proyecto es la confluencia de factores a través de un producto que posea valores artísticos sin alienar a la sociedad en la que vivimos, un producto híbrido que a la vez trascienda y entretenga. Veamos entonces cómo existen opiniones contrapuestas en lo referente a la cultura de masas:

Ya desde su primera edición en 1968 Umberto Eco advertía de las características de esta realidad en Apocalípticos e integrados (Lumen, 1984), libro esencial en el que se le atribuyen ciertas características a la cultura de masas: "Los mass media, inmersos en un circuito comercial, están sometidos a la ley de oferta y demanda. Dan pues al público únicamente lo que desea” (Eco, 1984, p. 46).

Sin embargo, no todos los teóricos que han indagado en este "nuevo" tipo de cultura han sido tan escépticos ni pesimistas. Alvin Toffler, en la introducción de La tercera ola (1979) afirma que "la desesperación no solo es un pecado (como dijo creo que fue C. P. Snow), sino que, además, está injustificada” (p. 8). 
Vivimos pues en un mundo ampliamente analizado bajo ópticas en ocasiones contrapuestas y que justificadamente generan debate en lo concerniente a la manera en la que son (o deben ser) consumidas o producidas las obras que, como escritores, guionistas o realizadores de contenido de masas, ponemos a disposición de las audiencias.

En este marco social contemporáneo, el guion se ubica en un limbo particular. Como obra de producción literaria palidece contra las otras posibilidades, como la poesía, la literatura o el teatro, por el simple hecho de no ser un producto escrito para ser vendido en librerías y leído por el amplio público. Ya que su esencia es la de ser una herramienta para contar una historia audiovisualmente termina por ser un subproducto, y al serlo debe encontrar la manera de encontrar el financiamiento necesario para poder realizarse audiovisualmente, de manera que no quede como un subproducto y llegue así a su máximo potencial.

Sin embargo, por ahora podemos afirmar que el guion debe cumplir con su autor y con su sociedad o su público que, en efecto, puede ser mercantilista o estetizado, pero también está lleno de oportunidades o posibilidades. Entre ellas, la garantía de realizar un guion que será consumido en su materialización como una película, de manera que el guion mismo no quede como un subproducto.

Al respecto, los especialistas en guion advierten la necesidad de satisfacer tanto las expectativas personales como las de la audiencia, como lo asegura Robert McKee en El guión (2009):

La diferencia por la mera diferencia es algo tan vacuo como el cumplir los imperativos comerciales a ojos cerrados. Después de trabajar durante meses o incluso años recopilando datos, recuerdos e invenciones para crear el tesoro que constituye el material de una historia, no hay ningún escritor serio que se aventure a enjaular su visión dentro de una fórmula o a trivializarla en fragmentaciones vanguardistas. La fórmula de lo "bien hecho" puede ahogar la voz de una historia pero las extravagancias del "cine de autor" le provocarán problemas de dicción. [...] El artista maduro nunca atrae la atención sobre sí mismo y el artista sabio nunca hace nada por el mero hecho de ir contra lo establecido (McKee, 2009, pp. 23-24).

De lo previamente mencionado podemos determinar que el cine, especialmente el de animación, es muy complejo. Como las demás artes narrativas, debe enfrentarse con un doble y contradictorio reto. Por un lado, debe ser auténtico en su 
propuesta narrativa, artística, estilística. Por el otro, debe satisfacer las necesidades de un público cuyos intereses artísticos pueden no ser los mismos del autor, y responden a motivaciones en ocasiones contrapuestas. Esto es especialmente cierto en el cine, medio que es muy caro realizar, razón por la cual los valores artísticos y comerciales de un producto deben estar balanceados de antemano, para que un producto sea atractivo y rentable. El cine de animación, siendo más complejo, caro y orientado a un público aún más segmentado, sufre más claramente este dilema.

Históricamente, el arte ha estado ligado al sistema de producción capitalista de la siguiente manera: el capitalismo industrial generó las vanguardias históricas, cuyo cuestionamiento de la sociedad devenía en utopía. El capitalismo de consumo generó la neovanguardia, que se dedicó a cuestionar la academia. La utopía fue abandonada y el arte se encontraba en el ámbito de la heterotopía. El capitalismo cultural en el que vivimos genera la llamada posvanguardia, que en realidad critica la cultura misma en una distopía artística.

La sociedad contemporánea es una en la que lo estético prevalece. E1 fácil acceso a la tecnología permite a un gran número de creadores dar a conocer sus obras y la proliferación de canales de distribución multiplican los públicos. En este contexto lo comercial se vuelve la norma, pues ante la feroz competencia es más posible destacar vendiendo un producto masivamente. La animación participa en este proceso de manera protagónica, al ser un medio regido por las exigencias del público. Ante esta coyuntura las opciones son dos: la distopía artística, capaz de remecer el mercantilista medio de la animación, aunque genere un impacto solo en círculos académicos o reducidos; o una propuesta que participe de lo comercial priorizando una poética propia; en suma, un punto medio, lo que afirmaba McKee líneas arriba. Para lograr este punto medio es necesario analizar y definir los aspectos en los que lo comercial debe dar paso a lo autoral y viceversa.

Sin embargo, los estudios que contrastan la poética de un autor con el público escasean, pues suelen enfocarse en otros aspectos de la toma de decisiones artística, incluso desdeñando al público en ocasiones. Sentenciaba Rodolfo Hinostroza en Los nuevos (1967): "No hay que engañarnos, amado Perú: tus lectores están a nivel de Reader's Digest, y solo tendrá éxito quien escriba poesía premasticada" (p. 68). ¿Será posible encontrar un punto medio que no aliene a la audiencia, pero que también la rete?

Los estudios utilizados para el presente análisis se centran en el problema teórico del consumo y las industrias culturales (Eco, Lipovetsky, Vargas Llosa, Toffler), las cuales generan una problemática para la producción artística contemporánea. Aterrizando este marco cultural en la producción del guion se ha recurrido a autores que incursionan en la narratología y la escritura de guiones 
(Genette, McKee). Sin embargo, se hace necesario un estudio específico para la animación, medio aún poco estudiado teóricamente.

De todo lo antes mencionado podemos plantear que es posible alcanzar el balance entre el cine de autor y el comercial en animación a través del equilibrio de elementos orientados a ambos tipos de cine entretejidos en la narrativa, estructura y poética del guion literario. Se desprende de esto que para lograr lo mencionado, las demandas de recepción de un público infantil y juvenil deben modificar la estructura, la línea de tiempo y demás decisiones de toda índole que afectan los eventos narrados y la construcción del guion en general.

Como en toda propuesta poética, la obra realizada puede - y debe- enmarcarse en una tradición a la cual se debe, a la que pertenece. De ahí se desprenden ciertas conclusiones y oportunidades para analizar las decisiones tomadas para determinar el valor de la propuesta, su capacidad de ruptura del molde o su adecuación a dicho molde. Nadie crea sobre el vacío. La tradición nos determina y nos ayuda a esclarecer la poética propia.

Por eso, en miras a lograr una película de animación orientada a la familia, pero con el suficiente espíritu de autor que le permita trascender, dicho proyecto debe analizar la tradición en la que se enmarca: antecedentes del cine de animación infantil y familiar que tienen numerosos exponentes en la actualidad. La pregunta es: ¿con qué guiones se identifica? ¿Cuáles son sus referentes? Difícilmente puede elegirse un grupo de películas de animación azarosamente y determinar que esa sea la muestra basada en la cual se deberá analizar una serie de factores para determinar la poética del cine de animación infantil que antecede a dicho producto híbrido, a medio camino entre lo autoral y lo comercial.

Ante la búsqueda de referentes para un producto híbrido se hace necesario analizar las categorías de lo comercial y lo autoral en una pequeña muestra de películas de animación orientada hacia ambos aspectos. Ninguna película es absolutamente personal o absolutamente comercial, pero sí hay películas que tienden a un camino o al otro. Adicionalmente, hay productos híbridos, que balancean adecuadamente ambas categorías. Nos concentraremos en estas categorías, rescatando una muestra de cada una de las tres regiones que nos interesan primordialmente: la industria hollywoodense, el cine mundial y el latinoamericano.

\section{Características del cine de animación infantil}

De acuerdo con las categorías de lo comercial y autoral establecidas, hemos elegido películas que se adhieren a una u otra categoría y, en la medida de lo posible, discutiremos brevemente sus valores en cuanto a su temática, estructura narrativa, 
género, personajes y estilo, para así poder dilucidar en qué aspectos de la propuesta poética recae cada uno de estos elementos y si pueden categorizarse como comerciales o autorales.

Adicionalmente a dicha categorización se ha elegido un título relacionado con la industria hollywoodense, un título del resto del mundo y un título del cine latinoamericano en cada categoría (comercial autoral e híbrida). La razón para esta categorización proviene de la manera en la que se organiza el cine de animación en los esquemas de producción actuales. Estados Unidos y Hollywood tienen una capacidad de producción hegemónica y altamente especializada, con altos presupuestos y públicos masivos alrededor del mundo. El resto del mundo debe producir a merced de las coproducciones, compartiendo los riesgos financieros, pues los públicos no suelen ser masivos, gran riesgo para producciones muy caras como suelen ser las animaciones. Un caso especial es el de Latinoamérica por dos razones: la cercanía a nuestro mercado y los esfuerzos mayores a nivel de financiación y captación de público. De ahí la razón de elegir estos tres sectores geográficos para generar la muestra de películas a comentar a continuación.

\section{Productos comerciales}

Como ya se ha mencionado, los productos comerciales son los que están diseñados, probablemente desde su concepción inicial, como un material de consumo para un público. Por ende, las decisiones tomadas giran en torno a esa concepción. Veamos de qué manera esas decisiones recaen en lo comercial o lo autoral según los ejes de discusión mencionados anteriormente. Según lo planteado, se ha elegido como representante del cine hollywoodense La vida secreta de tus mascotas (2016), del resto del mundo la francesa Mi villano favorito (2010) y de Latinoamérica la peruana Condorito (2017).

\section{Hollywood: La vida secreta de tus mascotas (2016)}

La vida secreta de tus mascotas cuenta la historia de lo que acontece durante el día mientras uno se va al trabajo y sus mascotas se quedan solas en casa. En el transcurso del día ocurren un sinnúmero de aventuras cómicas y descabelladas protagonizadas por perros y gatos adorables, con un diseño evidentemente orientado al marketing y la venta de merchandising. Si bien la premisa es original, parte de lo comercial, ya que es planteada como un concepto con el que el público se puede identificar rápidamente. La elección de animales como protagonistas absolutos es por la misma razón, ya que los niños se identifican con ellos y esto garantiza un éxito comercial. 
La estructura narrativa es lineal, simple y clara, con un par de flashbacks emotivos insertados en el camino y dos protagonistas claramente identificables, con diferencias de personalidad y un proceso de amistad que surge entre ellos. El conflicto del protagonista principal es que aparentemente va a ser reemplazado en el cariño de su dueña por el personaje secundario, en clara alusión a un probado éxito taquillero y comercial: Toy story. El género es aventura y comedia, los géneros probadamente más efectivos en el medio de la animación infantil. En ese sentido la exposición es breve y da paso a la acción, y el estilo es rápido y caricaturesco, para reforzar el énfasis cómico buscado.

Todos los elementos mencionados están alineados con el público y el cine comercial de una manera frontal. La fórmula se sigue hasta el límite de convertirse en un calco de otras películas. La vida secreta de tus mascotas es un referente del cine comercial que busca efectividad en la taquilla, y sus opciones nos ayudan a identificar lo comercial en la propuesta.

Mundo: Mi villano favorito (2010)

$M i$ villano favorito cuenta la historia de un genio criminal que tiene un plan macabro para robar la Luna, surgido de una rivalidad con otro supervillano. Para lograr sus planes adopta a tres adorables huérfanas que pueden ayudarlo, pero a costa de mucho esfuerzo y malos ratos se encariña con las niñas y se vuelve su amoroso padre.

El concepto aleccionador es claro, pero no tanto como su esfuerzo por comercializar el producto. Para ejemplificar basta con mencionar a los "minions", elementos absolutamente prescindibles en la trama, pero que la dominan. Una evidencia adicional es el uso del lenguaje, en este caso el inglés, para llegar a una audiencia mucho mayor que la que se podría lograr con el original francés.

En cuanto a la narrativa, es lineal y sencilla con unos cuantos saltos temporales utilitarios, siempre en busca de la comedia fácil. El protagonista es uno solo muy principal (el supervillano Gru) y el objetivo claro. El clímax con un tranquilizador final feliz termina de cerrar los elementos narrativos. El género es primordialmente comedia, con mucha acción y algunos elementos expositivos, siempre cómicos.

Esta película es muy popular. Su combinación de elementos funciona, pues están claramente pensados para el público. El principal elemento comercial descansa en la presencia de los minions, con una comedia física que no exige nada al espectador más que reírse de empujones y flatulencias. 


\section{Latinoamérica: Condorito (2017)}

Condorito cuenta la historia de un cóndor que debe recuperar un amuleto perdido para rescatar a su suegra Tremebunda de unos extraterrestres que la han secuestrado. En su ausencia, su novia Yayita es cortejada por Pepe Cortisona, y los amigos de Condorito deben evitar que esto ocurra.

La elección de Condorito, película peruana hecha con capitales mixtos y doblada por chilenos y mexicanos, es obvia. La búsqueda es un éxito comercial a través del uso de un personaje con una base de fans establecida y lograda. Esto genera un gran avance en lo comercial, como es en el caso de Minions (2015) y tantas secuelas que se producen actualmente. En el caso de Condorito no hay gran moraleja o enseñanza. Es puro entretenimiento. Los personajes son los que ya conocemos de la tira cómica, con sus conflictos previamente establecidos y personalidades gruesamente delineadas.

Algún interés recae en la estructura narrativa, que salta entre la aventura de Condorito y la de Yayita en Pelotillehue mientras evita a Pepe Cortisona. Sin embargo, el género vuelve a caer en lo mismo: aventura y comedia, poca exposición y mucha acción, y un estilo sencillo con impostación cómica.

E1 humor grueso de Condorito y sus lugares comunes a lo largo de la trama la ubican completamente dentro de la búsqueda comercial, casi sin alicientes personales. Es un personaje conocido al cual se le utiliza para atraer audiencias, haciendo de esta una propuesta puramente comercial.

\section{Productos autorales}

En contraste con los productos previamente mencionados, los guiones autorales reflejan preocupaciones personales de sus directores, usualmente autores del guion. Estas propuestas poéticas, al partir del autor y no del público, generan en ocasiones dificultades para levantar los fondos necesarios o las audiencias requeridas para recuperar la inversión, pero salen adelante. Del ámbito hollywoodense rescataremos Anomalisa (2015), del resto del mundo la francesa Las trillizas de Belleville (2003) y de Latinoamérica mencionaremos brevemente el histórico corto peruano del uruguayo Walter Tournier Nuestro pequeño paraíso (1983).

\section{Hollywood: Anomalisa (2015)}

Anomalisa es la curiosa historia de Michael Stone, un hombre casado que va a dar una conferencia en un hotel. Poco a poco descubrimos que Michael ve a todas las personas a su alrededor con la misma cara, y la misma voz. Nadie es diferente. 
Esto lo mantiene apático y amargado. Sin embargo, de pronto escucha una voz distinta, una mujer en una habitación contigua. Va a conocerla y también tiene una cara propia, diferente a la del resto. Ella se avergüenza de su cara, pues tiene una cicatriz, pero a Michael, acostumbrado a la uniformidad de rostros y voces, le parece hermosa y fascinante. La seduce y tiene sexo con ella en su habitación, y le propone huir juntos, pero poco a poco su cotidianidad, sus hábitos alimenticios, sus temas de conversación, hacen que Michael la empiece a ver como al resto, con la misma cara y la misma voz, por lo que, nuevamente amargado, regresa a su casa con su esposa y su hijo, ambos con la misma cara y voz que el resto del mundo.

Esta pequeña historia de gente pequeña encerrada en un pedestre hotel de Ohio está tan alejada de lo comercial como puede ser posible. No hay animales ni niños con los que el público pueda identificarse, ni siquiera hay verdaderos humanos (salvo Michael y Lisa); todos son autómatas idénticos. Las situaciones son humanas y cotidianas, y la escena de sexo es poco glamorosa, con personajes con cuerpos imperfectos e incómodos al quitarse la ropa frente a un extraño.

El concepto nihilista y alienante se suma al género (entre el drama y la comedia negra) para expresar intereses propios del autor, Charlie Kaufman, que ya ha explorado en otras obras como El ladrón de orquídeas (1999) o ¿Quieres ser John Malkovich? (2002). Concedamos que la película no es infantil ni familiar, pero de todas maneras necesita un público cada vez más ávido de entretenimiento ligero para escapar de la rutina. Esta película no hace concesiones de ese tipo. Está más concentrada en las preocupaciones del autor y su propuesta poética.

En esas líneas, la estructura narrativa es clara y sencilla. No hay riesgo de muerte, ni sobresaltos. La acción es estática, y tiene muchos diálogos y exposición otorgada por personajes con los que es difícil encariñarse o conectar.

\section{Mundo: Las trillizas de Belleville (2003)}

Otra historia curiosa, esta vez algo más aventurera. Madame Souza es una anciana con un nieto huérfano. El melancólico niño solo se interesa por las bicicletas y Madame Souza se vuelve su entrenadora hasta llevarlo al Tour de Francia. Sin embargo, el joven es raptado por la mafia para usarlo en carreras clandestinas. Madame Souza lo busca sin éxito y se alía con las trillizas de Belleville, tres ancianas que una vez fueron famosas cantantes y ahora son casi indigentes. Por azar encuentran al ciclista y escapan todos juntos.

La azarosa estructura de Las trillizas de Belleville, la curiosa elección del título, la anciana y lisiada protagonista, el melancólico objeto de su afecto, absolutamente falto de carisma y la riesgosa elección de hacerla una película muda son 
todas opciones poéticas propias de una propuesta personal, ajena a los cánones y expectativas del público.

El género es comedia y aventura, como en tantas películas comerciales, pero en Las trillizas de Belleville está tratado de una manera tan ajena, delirante y pasiva, que la aventura se diluye casi completamente dando paso a la contemplación. Los números musicales propios de los años 30 aportan una atmósfera surreal ajena a las propuestas comerciales a las que el público está acostumbrado.

\section{Latinoamérica: Nuestro pequeño paraiso (1983)}

Una breve mención para este esencial cortometraje peruano de nueve minutos. En él, un joven ve televisión y se ve mimetizado con lo que aparece en pantalla.

Por la brevedad de la trama no hay mucho que comentar a nivel de estructura, desarrollo de personajes o propuestas poéticas, pero el cortometraje de Walter Tournier es un evidente comentario social, con un protagonista poco agraciado físicamente y una estética "feísta" que choca directamente con los intereses de la audiencia. La elección de este cortometraje es porque, como se ha mencionado anteriormente, Latinoamérica es un territorio sin grandes posibilidades monetarias, donde las películas de animación se ven obligadas a ser productos comerciales para sobrevivir, pues no pueden ser subvencionadas por aparatos estatales proteccionistas ni grandes y multimillonarios estudios, como sí ocurre ocasionalmente en otras regiones del mundo.

\section{Productos híbridos}

Por lo expuesto anteriormente, nuestro interés principal radica en los productos híbridos, que saben balancear lo comercial y lo autoral adecuadamente, para no alienar a su público y así no representar una inversión fallida. Además, intentan dar un alma a sus productos, una personalidad propia, una poética. La muestra elegida, como las anteriores, se ubica en las tres regiones mencionadas previamente. Del cine de Hollywood rescataremos Los Increíbles (2013); del resto del mundo, la japonesa $M i$ vecino Totoro (1988); y de Latinoamérica, la argentina Metegol (2013).

Hollywood: Los Increíbles (2013)

Los Increíbles se enmarca en una antigua tradición de cine de superhéroes. Luego de rechazar la ayuda de un pequeño fan y hacer muchos destrozos salvando a un grupo de gente de un supervillano, el Sr. Increíble debe ir con su familia al 
anonimato, pues los superhéroes, una vez amados por ser la salvación de la ciudad, ahora son considerados una amenaza. Pasan los años y el Sr. Increíble vive con su esposa y sus hijos, todos con superpoderes, en el anonimato y la mediocridad, hasta que es convocado a probar un peligroso robot. Al hacerlo se percata de que es una trampa de Síndrome, el niño que alguna vez rechazó y que ahora, convertido en supervillano, quiere eliminar a todos los superhéroes. Su esposa, Elastichica, se entera y va a rescatarlo junto con sus hijos. Después de lograrlo salvan a la ciudad de un ataque de Síndrome, devolviéndole la credibilidad a los superhéroes.

Los Increíbles es una aventura como muchos de los productos comerciales mencionados anteriormente. Se inserta tan cómodamente en la tradición del cine de superhéroes que es difícil distinguirla en papel de otras obras. Sin embargo, tienen una complejidad narrativa mucho mayor, con subtemas evidentes concernientes a la crisis de mediana edad, el matrimonio, la infidelidad y la familia. Personajes menores como Mirage, ayudante de Síndrome, tienen motivaciones complejas y casi todos los personajes tienen una curva de crecimiento propia. Los riesgos propios de la aventura aquí se sienten muy serios, y la muerte ronda a los personajes a cada momento.

La estructura narrativa es lineal, aunque hay un prólogo extenso y ciertos momentos de exposición, sobre todo en el primer acto. Todo esto alarga la duración de la película, haciéndola una de las más largas de la animación mainstream norteamericana. Las motivaciones personales del director y guionista Brad Bird (Ratatouille, El gigante de hierro) son evidentes, con su énfasis en la ambientación atemporal y guiños al futurismo sesentero.

Mundo: Mi vecino Totoro (1988)

Mi vecino Totoro cuenta la tierna historia de dos niñas que se mudan con su padre a una casa de campo para estar cerca de su madre enferma que se recupera en un hospital. Viñetas de la vida de campo se suceden una tras otra siempre con un énfasis en el mundo natural y espiritual, con su culminación en un personaje llamado Totoro, un duende del bosque que visita a las niñas y las ayuda en pruebas en ocasiones divertidas, en ocasiones didácticas y en ocasiones dramáticas, como el extravío de la hermanita menor, que hace a todos en el pueblo temer lo peor, hasta el momento en que Totoro ayuda a encontrarla. Finalmente la madre vuelve a casa recuperada para estar con su esposo y sus hijas.

De todas las películas analizadas, Mi vecino Totoro tiene la estructura más particular. No es aristotélica, sino episódica. No cuenta una historia ni una aventura, sino una serie de pequeños eventos casi inconexos narrativamente, aunque con 
personajes similares. Estos eventos van volviéndose más relevantes e interesantes hasta lograr su "clímax" en el rescate de Mei, la hermana menor. Sin embargo, nunca se logra nada, no hay una búsqueda, no hay aventura. Ni siquiera hay comedia, solo muchos momentos tiernos y plácidos. En ese sentido, hay algo de exposición y cuando hay acción esta es pausada, calmada. El estilo es, en definitiva, muy personal y diferente al resto de películas.

Entonces, ¿qué hace de Mi vecino Totoro un producto híbrido? Su adhesión a una serie de decisiones pensadas en el público. Por ejemplo la de las edades de las niñas, los momentos didácticos esparcidos por la película, la moraleja ambientalista y espiritual, la general placidez de la narrativa y diseño de los personajes. Si se compara esta obra con otras de Hayao Miyazaki, pueden encontrarse similitudes temáticas y estilísticas con Mi vecino Totoro.

\section{Latinoamérica: Metegol (2013)}

Metegol es una historia acerca de un joven aficionado al futbolín, cuyo pueblo es atacado por una vanidosa estrella del fútbol profesional que destruye su futbolín y prácticamente secuestra a la chica que ama. Él hace de todo por recuperar su futbolín, su chica y su pueblo hasta que es retado por el futbolista a un partido de verdad. Él reúne a un equipo de perdedores y se enfrenta con pasión a un equipo de estrellas. A pesar de perder el partido, gana el respeto de su chica y termina casándose con ella y teniendo un hijo, con quien comparte su pasión por el futbolín.

Metegol cumple con todo lo requerido de una película comercial de animación. Tiene aventura, comedia, mucha acción, personajes entrañables, momentos sentimentales, posibles derrotas, sueños de victoria, etc. Además, su temática es, inteligentemente, el fútbol, deporte que mueve multitudes. Aparentemente, con la pérdida final del equipo revierte lo que parecería ser la regla en una película para toda la familia: el final feliz. Sin embargo, no lo hace. El final es feliz, solo que no ganan. Pero se queda con la chica, forma una familia, arregla su futbolín, se vuelve un héroe.

Con esta película, Juan José Campanella (El hijo de la novia, El secreto de sus ojos) incursiona en la animación con una película aparentemente diferente a las anteriores, pero que en realidad comparte ciertos elementos temáticos orientados a la familia, el romance y sobre todo el fútbol, presente siempre de una manera particular en su filmografía. Los intereses personales y el manejo sensible de la narrativa le dan a Metegol un afán más personal. 


\section{Resultados}

\section{Identificación de elementos comerciales}

De acuerdo con lo expuesto, se desprende que hay ciertos elementos que pueden identificarse como comerciales, siempre y cuando estén adheridos a un público particular. Para efectos de este estudio, consideraremos como comercial todo lo dirigido a un público infantil o familiar únicamente. Las categorías que brevemente analizaremos estarán referidas a la temática, estructura, género y personajes.

\section{Temática}

La temática es en general libre, con todo tipo de temas siendo explorados. Existen los deportivos, naturales, fantásticos, realistas o surreales. Lo que suele primar es la participación de dinámicas familiares, que determinan la conexión necesaria con la audiencia; más allá de eso, este tema es bastante libre.

\section{Estructura}

La estructura obligatoriamente debe ir a lo sencillo, evitar los flashbacks (aunque esto no es prohibitivo) o dejarlos en lo mínimo y simplificar la cantidad de personajes con una línea narrativa clara. Suele haber narradores diegéticos que ayudan a dar la idea de cuento o fantasía, pero esto tampoco es absolutamente necesario.

\section{Género}

Los géneros obligatorios para lo comercial son la aventura y la comedia. Es permitido insertar elementos dramáticos como parte de la narrativa, pero el género debe enmarcarse en los establecidos para que la obra funcione comercialmente.

\section{Personajes}

Aquí hay dos imperativos, aunque no son determinantes. Debe haber al menos un niño, una niña o un animal. Esto es para la inmediata identificación de los pequeños con las historias contadas. Ante la ausencia de ambos, no tendrán con quién identificarse ni a quién encontrar marketeable, y el proyecto no funcionará comercialmente.

Los datos previamente expuestos no son antojadizos. Las películas citadas tienen estos elementos trabajando estratégicamente en sus tramas, de manera que funcionen comercialmente. Los que no (por ejemplo, Anomalisa) son los que 
no tienen intenciones comerciales, o en cualquier caso priorizan las propuestas poéticas como desglosaremos a continuación.

\section{Identificación de elementos autorales}

Una tipificación de lo comercial se hace de alguna manera más sencilla que una de lo autoral. La razón es que los públicos son y seguirán siendo estudiados y analizados para sacar la mayor ventaja comercial de los productos lanzados, por lo que las "fórmulas" existen. Por otro lado, en lo autoral hay tantas posibilidades como hay autores, pues las propuestas deben alinearse a ellos para considerarse autorales. Con todo esto, intentaremos hacer una breve reseña de lo que puede constituirse como autoral en los cuatro ejes mencionados previamente, es decir, la temática, la estructura, el género y los personajes.

\section{Temática}

Como se ha mencionado previamente, la temática es libre, ya que tanto películas comerciales como autorales — e híbridas - tocan temas variados y disímiles. Sin embargo, se puede decir que para que un tema sea verdaderamente autoral este debe conectar de una manera personal con el autor. Esto solo puede conocerlo un espectador luego de estar expuesto al corpus de la obra de un autor. No puede determinarse con una única obra. Puede verse en Miyazaki (elementos naturales y espirituales), Bird (ambientación futurista), Campanella (uso del fútbol), Kaufmann (exploración de universos paralelos), entre otros nombres mencionados previamente.

\section{Estructura}

Las estructuras narrativas pueden variar también. Los ejemplos citados incluyen una estructura episódica ( $M i$ vecino Totoro), una aventura errática y azarosa (Las trillizas de Belleville), una estructura minimalista (Anomalisa). De hecho, otros ejemplos como Despertando a la vida de Richard Linklater van más allá, con estructuras desordenadas, inconexas y deliberadamente nebulosas. También hay autores que optan por la claridad expositiva, mientras que sus proyectos siguen siendo absolutamente personales, como algunos ejemplos de Richard Williams. Sin más, la estructura puede considerarse autoral cuando conecta con el autor, principalmente cuando no sigue el esquema clásico que está probadamente insertado en las expectativas de la audiencia. 


\section{Género}

El género primordial de un autor alejado de un público tendría que ser el drama, aunque muchos otros géneros pueden apelar a una poética personal sin necesariamente alienar a un público, como es el caso de la ciencia ficción, la comedia negra, etc. Sin embargo, en el caso del drama, si excede la cuota suficiente para que el público conecte con una historia sin llegar a deprimirse durante la extensión de la película, podríamos decir que estaría entrando en el terreno de lo personal y alejándose de la audiencia, como ocurre con la mentada Anomalisa.

\section{Personajes}

En el cine de animación infantil y familiar abundan los niños, sea que la película es autoral, comercial o híbrida. Sin embargo, los personajes principales también pueden ser adultos, ancianos, no humanos. Lo que necesite el autor para generar la conexión personal necesaria entre él y su obra. Es el caso de Las trillizas de Belleville y Anomalisa.

Como había sido mencionado, una tipificación de lo autoral es necesariamente general y en cierto modo libre, azarosa.

\section{Conclusiones}

En la búsqueda de producir un guion para animación infantil en el Perú es ideal intentar encontrar un punto medio entre lo comercial y lo autoral, para crear una obra que trascienda sin alienar al público tan necesario para una obra de este tipo. Así, se vuelve imperativo proponer una obra híbrida. Para lograrlo, es imprescindible analizar la tradición en la que el guion se enmarca, a fin de incorporar ciertos elementos comerciales en una poética personal, propia de cada autor. Dichos elementos son los siguientes: priorizar las temáticas con dinámicas familiares y ubicar al centro de dicha temática a un niño o niña, sea humano o animal; formular una estructura clásica aristotélica evitando los saltos temporales y priorizando la claridad expositiva; narrar historias dentro de los géneros de comedia y aventura. Estos elementos comerciales, probados a través del análisis y comparación de películas comerciales, pueden devenir en fórmula si no se aplican a un tratamiento autoral de la temática o estructura narrativa del guion. Con estas decisiones balanceadas se puede conseguir un producto híbrido que trascienda como obra artística de un autor a la vez que apele a un público. 


\section{Contribución del autor}

Luis Ángel Esparza Santa María ha participado en la elaboración, la compilación de datos, la redacción y el consentimiento de la versión final del presente artículo.

\section{Fuente de financiamiento}

La investigación es autofinanciada.

\section{Conflictos de interés}

Ninguno.

\section{Trayectoria académica}

Luis Ángel Esparza Santa María es magíster en Escritura Creativa por la Universidad Nacional Mayor de San Marcos. Realizó sus estudios de pregrado en Comunicación en la Universidad de Lima. Desde su egreso se dedicó a la producción de animación y recibió tres premios del Ministerio de Cultura como incentivos a la producción, además del fondo Ibermedia. Es profesor de Guion y Cine en la Universidad de Ciencias y Artes de América Latina, ha publicado un artículo en la revista Butaca Sanmarquina y ha participado de ponencias en festivales de animación en Chile (Chilemonos) y el Perú (Anima Perú).

\section{Referencias bibliográficas}

Cevallos, L. (1967). Los nuevos. Editorial Universitaria.

Eco, U. (1984). Apocalipticos e integrados. Lumen.

McKee, R. (2009). El guión. Alba Editorial.

Toffler, A. (1980). La tercera ola. Plaza \& Janes.

Vargas Llosa, M. (2012). La civilización del espectáculo. Alfaguara. 